Profesor de Literatura Hispanoamericana de la Universidad de Alicante. Ha publicado numerosos estudios y ediciones sobre autores españoles e hispanoamericanos, entre ellos Miguel Hernández, al que dedicó varios trabajos hasta la edición de las Obras Completas en 1992. En el campo latinoamericano, destacan sus estudios y ediciones sobre Pablo Neruda, José María

\title{
NERUDA Y NOSOTROS, LOS DE ENTONCES
}

Arguedas y temas referentes a la identidad cultural. En la actualidad trabaja sobre literatura colonial hispanoamericana $y$ sobre el siglo XVIII novohispano.

\author{
JOSÉ CARLOS ROVIRA
}

El recurso del título es demasiado fácil para que me centre en él. Decir «nosotros, los de entonces, ya no somos los mismos", no sería la resolución a ningún enigma. Sería a lo mejor la constatación de algo evidente que podríamos ambientar con el pianista Sam y "El tiempo pasará" de la película Casablanca. Quizá lo que he intentado indicar con el título es solamente la recepción de Neruda por una franja generacional que coexistimos en tiempo, muy jóvenes, con un poeta que era grandioso en nuestra lengua y nuestra memoria.

Pablo Neruda como recurso memorial por tanto. Memorial de Neruda con la perspectiva de 25 años. Entre los repasos a lo que ya dijimos sobre el poeta, hace tiempo, me quedan sobre todo recorridos ordenados por lo que dijeron algunos críticos e historiadores de la literatura entre los que varios de ellos, principales, han hablado y van a hablar estos días entre nosotros. No sé si en mi lectura ordenada de Pablo Neruda, allá por el 91, aporté una nueva perspectiva más allá del orden. Tampoco sé si en mi edición comentada de Veinte poemas de amor y una canción desesperada en $1997^{2}$ dije algo que no fuera un conjunto de ideas de lector sobre un libro que uno hubiera querido escribir. Manifiesto mi desconcierto sobre lo dicho y escrito porque lo que pretendo ahora es emplazar a Neruda en recuerdos. Me perdonarán este devaneo con la memoria que seguramente no significa mucho. Me perdonarán que atente contra la teoría de la recepción con una recepción que a lo mejor, por personal, se convierte en emotiva y por tanto insufrible. Me perdonarán que omita la vocación académica para contar un Neruda que tiene que ver sobre todo con historias del corazón y la razón.

\section{PRIMERA MEMORIA}

Este poeta era inevitable en su ofrecimiento de versos. He dicho ya alguna vez que hay escritores que memorizamos sin querer. Poetas sobre todo de los que recordamos versos. Hay otros poetas, que hemos leído, de los que no recordamos ninguno. Es un enigma selectivo. Debe haber alguna parte del cerebro que relaciona versos formidables con situaciones más o menos intensas. La divinidad que nos construyó debió pensar que la poesía debía mezclarse intensamente con la vida. Desdichados de aquéllos que no la mezclen.

Recuerdo inicialmente, claro, al Neruda que escribió poesía de amor. Al Neruda que escribió tanta poesía de amor que colmó medidas. Recuerdo a alguien que dejó de escribir poesía, que dejó de intentar ser poeta, cuando se dio cuenta de que Pablo Neruda escribió los Veinte poemas de amor allá por sus dieciocho años. Era inevitable desanimarse ante aquel torrente de palabras que evocaban situaciones de amor, pasados y presentes, imposibles futuros, con una magia verbal que se convirtió en irrepetible, aunque fuera imitable. El desanimado poeta al que me refiero, recorrió varias veces en la memoria aquello de «puedo escribir los versos más tristes esta noche», se dio cuenta de las noches estrelladas, o de que efectivamente las estrellas tiritan, notó la magia verbal de aquel encantador de la palabra y supuso que era difícil emular todo aquello.

Lo malo de la poesía es si sirve de envenenadora del recuerdo, lo malo de la poesía es si alguien acaba de decirse en serio, frente a formulaciones más sencillas, aquello de que
1

José Carlos Rovira, Para leer a Pablo Neruda, Madrid, Palas Atenea, 1991.

2

Pablo Neruda, Veinte poemas de amor y una canción desesperada, edición de José Carlos Rovira, Madrid, Espasa Calpe, 1997.

Neruda y nosotros, los de entonces JOSÉ CARLOS ROVIRA 
Raúl González Tuñón, Poemas de Buenos Aires, Buenos Aires, Torres Agüero editor, 1983, pág. 15. "Eche veinte centavos en la ranura" pertenece al libro De el violín del diablo.

\section{4}

Recuérdese la obra principal de Alain Sicard, El pensamiento poético de Pablo Neruda, Madrid, Gredos, 1981, en donde el despliegue de la obra de Neruda se realizaría a partir de la idea título de Tentativa de hombre infinito y de la imposibilidad de esta infinitud, generadora de la angustia del tiempo de las residencias.

\section{5}

Sigo considerando esta lecturo clásica y primera de Neruda como principal: Amado Alonso, Poesía y estilo de Pablo Neruda, Barcelona, Edhasa, 1979 (la primera edición es de 1940). Su lectura de la primera producción como el paso "de la melancolía» (amorosa) a «la angustia» (de las residencias) y la relación de estos espacios con la poesía histórica y social sucesiva me parece no superada.

\section{6}

Son varias las lecturas en las que Loyola concretó su propuesta: desde Hernán Loyola, Los modos de autorreferencia en la obra de Pablo Neruda, Santiago, Ed. Aurora, 1964, hasta las notas introductorias a los diferentes apartados en Pablo Neruda, Antología poética, ed. de Hernán Loyola, Madrid, Alianza editorial, 1981.
Neruda y nosotros, los de entonces JOSÉ CARLOS ROVIRA «emerge tu recuerdo de la noche en que estoy».

Atención. Tomemos distancias. Diseñemos máquinas para el futuro, expendedoras de fragmentos poéticos ante un tiempo en el que va a quedar poco espacio para la poesía. $\mathrm{Me}$ imagino que todos recuerdan aquel poema de Raúl González Tuñón, argentino evocado por nuestro Miguel Hernández, que se titula: "Eche veinte centavos a la ranura" y que escribió en $1926^{3}$. Es un poema esencial de la modernidad, que concluye:

Y no se inmute amigo, la vida es dura, con la filosofía poco se goza.

Si quiere ver la vida color de rosa

eche veinte centavos en la ranura.

Para el tiempo que viene, seguro, habrá máquinas nerudianas en las esquinas, o a lo mejor será un recurso de Internet el que nos devuelva, tras el pago codificado de un euro, un fragmento de poesía. Por ejemplo:

Juegas todos los días con la luz del universo, Sutil visitadora, llegas en la flor y en el agua.

Eres más que esta blanca cabecita que aprieto

Como un racimo entre mis manos cada día.

La primera memoria se nos aniquila así, con la incitación a esa máquina que nos entregue fragmentariamente versos y recuerdos de Neruda. El fin de siglo está a dos pasos y su locurita, como dijo otro poeta, ya encandila. Clausuremos la primera memoria que es la del poeta joven, intenso de palabras, repleto de retóricas de amor modernizadas. Demos paso a sucesivos Nerudas y a otras inevitables memorias.

\section{SEGUNDA MEMORIA}

«El río que durando se destruye». Heráclito y nosotros. Neruda y nosotros como residentes en la tierra. Invirtiendo a Heráclito. Un día, en Rangoom por ejemplo, advierte que la tierra es un conjunto de destrucciones. «Tentativa de hombre infinito y su fracaso», nos dirá Alain Sicard ${ }^{4}$, que está por aquí cerca. La naturaleza nos indica también nuestra propia finitud. El fluir de las cosas es destrucción. Amado Alonso y su lectura imprescindible 5 . El poeta como testigo de la destrucción, que nos dijo Hernán Loyola ${ }^{6}$. Una clave esencial, la de las destrucciones, que creó un tiempo metafísico y surreal, con un surrealismo tan nuestro que se escribía en nuestra propia lengua. Un extraño enigma de lenguaje de los sueños en el que el «Caballo de los sueños» es la ansiedad irrealizable del tiempo desde nuestra cotidianidad reiterada:

Innecesario, viéndome en los espejos, con un gusto a semanas, a biógrafos, a papeles, [...]

Vago de un punto a otro, absorbo ilusiones converso con los sastres en sus nidos, ellos, a menudo, con voz fatal y fría, cantan y hacen huir los maleficios.

Hay un país extenso en el cielo con las supersticiosas alfombras del arco iris, y con vegetaciones vesperales; hacia allí me dirijo, no sin cierta fatiga, pisando una tierra removida de sepulcros un tanto

[frescos...

El tiempo se nos va haciendo inevitable ahora. Irremediable. El océano también tiene un sur que es desde donde nos mira el tiempo detenido. Es un sur del océano donde se acumulan destrucciones. La luna también es destructora, como la sal:

De consumida sal y garganta en peligro están hechas las rosas del océano solo, el agua rota sin embargo, y pájaros temibles...

Comprendimos el tiempo con Neruda y sus destrucciones. Sentimos el tiempo destruido como ese reloj desvencijado que corre bajo el agua temible en otro de los poemas de Residencia en la tierra:

Hay tanta luz sombría en el espacio

y tantas dimensiones de súbito amarillas, porque no cae el viento

ni respiran las hojas.

Es un día domingo detenido en el mar, un día como un buque sumergido, una gota de tiempo que asaltan las escamas ferozmente vestidas de humedad transparente...

Pero este Neruda, que ve destrucciones solamente, se encontrará muy pronto con la residencia en una historia que también fue muy destructiva, aunque a partir de ella pudiera plantearse la reconstrucción. 


\section{TERCERA MEMORIA}

Madrid, 1936: «España en el corazón» de la Tercera residencia. Conozco a alguien que nació diez años después de acabada la guerra civil, la española. Eran todavía los años de penitencia, que llamó Carlos Barral en sus memorias y que nos había impuesto aquél cuyo nombre, afortunadamente, ya no consigo recordar. Los años de penitencia fueron sobre todo los de la imposición de una memoria grandilocuente e imperial en la que no cabían contradicciones ni matices. La literatura, es cierto, nos rescató de aquella oleada de memoria azul y vengativa. Lecturas de Hernández al atardecer allá por los quince años, lectura sobrecogida de Los grandes cementerios bajo la luna de Georges Bernanos, lectura sorprendida de aquel poeta cuya Tercera residencia salía de la maleta de un librero de la calle mayor que se llamaba Manolo Rey. No tomen los jóvenes lo que digo como impudor autobiográfico puesto que lo que cuento es bastante generacional. Sí, desde luego, sólo para los que leían libros la literatura nos podía rescatar a un tiempo que se había intentado aniquilar no sólo con prohibiciones, sino con pelotones de fusilamiento.

Neruda entonces, explicando algunas cosas, en medio de aquella memoria:

Preguntaréis: $Y$ dónde están las lilas?

Y la metafísica cubierta de amapolas?

Y la lluvia que a menudo golpeaba

sus palabras llenándolas de agujeros y pájaros?

Os voy a contar todo lo que me pasa.

Yo vivía en un barrio

de Madrid, con campanas,

con relojes, con árboles.

$[\ldots]$

Mi casa era llamada

la casa de las flores...

$[\ldots]$

Todo

eran grandes voces, sal de mercaderías,

aglomeraciones de pan palpitante,

mercados de mi barrio de Argüelles con su estatua como un tintero pálido entre las merluzas

[...]

Y una mañana todo estaba ardiendo

y una mañana las hogueras

salían de la tierra

devorando seres, y desde entonces fuego,

pólvora desde entonces,

y desde entonces sangre.

[...]

Preguntaréis por qué su poesía

no nos habla del suelo, de las hojas,

de los grandes volcanes de su país natal?

Venid a ver la sangre por las calles,

venid a ver

la sangre por las calles,

venid a ver

la sangre por las calles!

\section{CUARTA MEMORIA}

Conozco a alguien que consiguió por fin en 1997 subir a ese Monte Carmelo de la materia que es Macchu Picchu. Recomiendo el lugar pues es imprescindible para la geografía peruana y nerudiana. Y por su belleza, por supuesto. Estoy hablando de 1997 y de un recorrido que tenía que enlazar, obligatoriamente, con otra lectura temprana, como de treinta años antes, con "Alturas de Macchu Picchu” del Canto General. Hay situaciones que uno espera tanto tiempo que, necesariamente, acaban siendo diferentes, cuando se producen, a lo previsto. Preconcebidamente se puede buscar la «alta ciudad de piedras escalares», «la plata torrencial del Urubamba», a «Wilkamayu de sonoros hilos», para recrear en una geografía por fin vivida el momento épico de recitación:

\section{Sube a nacer conmigo, hermano. \\ Dame la mano desde la profunda \\ zona de tu dolor diseminado,}

pero allí donde Neruda, hacia 1945, quiso interpretar el espeso silencio de la ciudad incaica, dar la palabra al pasado, llamar a la regeneración americana, encontrarás quizá, pasado el tiempo, más que un paraje mítico, más que una llamada de la historia, el sonido de las cámaras Kodak de los turistas que te acompañan. Es la sensación que ya dejó escrita el poeta peruano Martín Adán en un texto que invertía la transcendencia nerudiana hacia la cotidianidad más definida.

Dice Martín Adán en La mano desasida

Nunca del numen, simple piedra,
Martín Adán, La mano desasida, en El más hermoso crepúsculo del mundo (Antología), estudio y selección de Jorge Aguilar Mora, México, FCE, 1992, pág. 250.
Neruda y nosotros, los de entonces JOSÉ CARLOS ROVIRA 
viste subir tanto fantasma

con el Cicerón, el sandwich, la Kodak y la maleta...

Viste tanto desde tu armonía

y simpatía de tus ojos duros y miradas dipersas...

Yo soy el que sube

por sobre tus flores inodoras y tus írritas pencas!

¡Yo soy el que sube a sí mismo!

¡Yo soy el de mi trágica constante primavera

¡No yerres, Macchu Picchu!

¡Viste tanto desde tu ceguera!...,

invirtiendo la transcendencia regenerativa e histórica de Neruda, veinte años después de que el poeta Chileno construyera sus "Alturas de Macchu Picchu" como centro de la historicidad y miticidad combativa del Canto General.

Aunque en 1997, retomando la memoria, no serán seguro los disparos de las máquinas fotográficas las que te impedirán interpretar el silencio para regenerar, a partir de él, la historia. Quizá sea la misma historia la que te impida reinterpretar el silencio, recrear el mito, reconsiderar la posición de profeta de la salvación de un continente.

El hotel «Ruinas de Macchu Picchu» será un buen refugio para una tarde lluviosa, en la que la televisión ha anunciado que un monte se ha disuelto por las lluvias de la semana anterior sobre la vecina $y$ arguediana Abancay, con doscientos muertos en el barro. El hotel «Ruinas de Macchu Picchu» es un refugio espléndido para quedarse sin luz toda una noche y refugiarse tras una vela en una memoria perdida, garabateando papeles y recuerdos. Te pondrás a recitar entonces aquello que casi cierra el Canto General:

Me has dado la fraternidad hacia el que no conozco.

Me has agregado la fuerza de todos los que viven.

Me has vuelto a dar la patria como en un [nacimiento.

Me has dado la libertad que no tiene el solitario.

Me enseñaste a encender la bondad, como el fuego. [...]

Me has hecho indestructible porque contigo no termino en mí mismo.

Y cuando te des cuenta de que te estás recitando el poema "A mi partido" bajarás otra vez al bar, casi clandestinamente: «Camarero, por favor, otras dos botellas de pisco».

\section{QUINTA MEMORIA}

Ya has contado alguna vez tu primer encuentro con Capri, allá por noviembre de 1985. La llegada en barco desde Nápoles en un día de sol en el golfo y en la tierra. La aproximación al puerto de la isla mientras el tiempo cambiaba y se levantaba un viento y caía una llovizna, y un solitario recitaba en la proa, ante la mirada de un grupo de japoneses espantados, aquello de:

El viento es un caballo:

óyelo como corre

por el mar, por el cielo.

Quiere llevarme: escucha

cómo recorre el mundo

para llevarme lejos.

La isla, lugar de varios regresos, las islas en definitiva, se convirtieron a través de Neruda en un lugar memorial que confluía en la reconstrucción de la isla como eros:

Toda la noche he dormido contigo

junto al mar, en la isla.

Salvaje y dulce eras entre el placer y el sueño, entre el fuego y el agua...

"La noche en la isla" de Los versos del capitán reconstruye en 1952 un tiempo de expresión amorosa en el que Pablo Neruda vuelve a andar los caminos abiertos en 1924 con Veinte poemas de amor y una canción desesperada. Han pasado veintiocho años y un recorrido complejo de escritura fundamental y fundacional para la poética del autor. Neruda tiene 48 años cuando en las prensas de Paolo Ricci aparecen en Nápoles Los versos del capitán. El libro se publica anónimo y en una bellísima edición que no tuvo más de cincuenta ejemplares. Las razones de aquella anonimia han sido interpretadas a través de dos niveles personales: uno, correspondiente a la biografía privada, habla de lo mal que le habría sabido a la ex-compañera del poeta, Delia del Carril, sus andanzas amorosas con Matilde Urrutia en la Isla de Capri; otro, correspondiente a la biografía pública, tiene que ver con una restricción que el senador comunista Neruda se habría impuesto, exiliado de su país por la persecución de González Videla, después de publicar en México su Canto general con llamadas a la construcción 
de la historia, para no incurrir en la frivolidad imperdonable de un nuevo libro de amor, cargado de un apasionado erotismo, de recorridos corporales, en una isla que es viento, es risa y es cuerpo.

La explicación última de la anonimia nos da lo mismo: el prólogo de 1952 era una carta firmada por Rosario, la destinataria de aquellos versos, en las que decía haber transcrito los originales de quien fuera su gran amor, un capitán de la guerra de España al que había encontrado tras la derrota, en la frontera franco-española:

él venía de la guerra de España. No venía vencido. Era del partido de Pasionaria, estaba lleno de ilusiones y de esperanzas...

Las claves de aquel episodio de amor son narradas como proyección de la historia vivida, como afirmación de un tiempo pasado que transformó sus vidas, mientras la historia reciente confluye de manera rotunda en el héroe épico y lírico que ha llenado de amor a la protagonista y autora del prólogo:

Me hizo sentir que todo cambiaba en mi vida[...] No sabía de sentimientos pequeños, ni tampoco los aceptaba. Me dio su amor con toda la pasión que él era capaz de sentir y yo lo amé como nunca me creí capaz de amar. Todo se transformó en mi vida. Entré a un mundo que antes nunca soñé que existía. Primero tuve miedo, hubo momentos de duda, pero el amor no me dejó vacilar mucho tiempo. Este amor me traía todo. La ternura dulce y sencilla cuando buscaba una flor, un juguete, una piedra de río y me la entregaba con sus ojos húmedos de una ternura infinita.

Sólo en 1963, once años después de su aparición, el anónimo autor rescatará el libro que aparecerá en sucesivas ediciones ya con el nombre del poeta chileno, aunque prácticamente desde 1952 todos los interesados en el escritor sabían que era suyo.

Los versos del capitán son en cualquier caso una primera restricción hacia un ámbito privado al que Neruda volverá otras veces. El amor se resuelve como salvación y algunas claves del libro recogen explícitamente esto: el poeta que se ahogaba en su tentativa imposible de hombre infinito, aquel al que acosaba una naturaleza destruida y destructora que confluía en una angustia de tiempo y espacio imposible de abarcar, en la «tentativa de hombre infinito y su fracaso» que Alain Sicard consideró síntesis de la primera poética, observa ahora que la amada es precisa y efectivamente «La infinita», como dice el título de uno de los poemas, cuerpo inabarcable pero posible:

En ese territorio

de tus pies a tu frente,

andando, andando, andando,

me pasaré la vida.

"En ti la tierra", el poema que abre el libro, es parte de esa infinitud descubierta, entre sensaciones, recorridos corporales, naturalezas que se van acumulando a una descripción del cuerpo de la amada, recuerdos literarios como la inevitable presencia, ya duradera, de San Juan de la Cruz y su Cántico espiritual:

Arañaré la tierra para hacerte una cueva

y allí tu capitán

te esperará con flores en el lecho,

dice Neruda en "la carta en el camino", como recuerdo explícito de San Juan. Pero lo más importante me parece ahora el entorno insular que descubre este libro de amor. La imagen insular y marina que lo recorre. Una vez es "El viento en la isla":

El viento es un caballo:

óyelo como corre

por el mar, por el cielo,

para llegar Neruda a refugiarse del viento, que quiere llevarlo lejos, en todos los espacios de protección que le ofrece la amada: los brazos inevitables, la boca, hasta los ojos omnipresentes:

\footnotetext{
Deja que el viento corra

coronado de espuma, que me llame y me busque galopando en la sombra, mientras yo, sumergido bajo tus grandes ojos, por esta noche sola descansaré, amor mío.
}

"Epitalamio", casi al final del libro, redescubre un espacio de memoria reciente y compartida:
Neruda y nosotros, los de entonces JOSÉ CARLOS ROVIRA 

en el itinerario de Neruda", Pablo Neruda. Cinco ensayos, Roma, Bulzoni, 1996, págs. 62-63.

\section{Recuerdas cuando}

en invierno llegamos a la isla?

El mar hacia nosotros levantaba

una copa de frío.

El encuentro amoroso ha transformado al poeta, y a la mujer que ahora recupera sus identidades terrestres y marinas: la mujer es agua de las olas, agua marina, algas, luna nueva, germinaciones que trae el agua a la tierra seca. Todo ello como inversión rotunda del mar que era tiempo destructor en las Residencias, y allí concretamente en poemas como “El sur del océano". Ahora el sujeto poético se desacraliza, pierde la solemnidad del autor épico que había modulado el Canto general, para convertirse sucesivamente en un tigre, un cóndor o un insecto, que recorre el cuerpo de la amada, o para crear un autorretrato imprevisible para quien desde hacía años estaba jugando al retrato póetico y profético de la solemnidad épica reciente o de la solemnidad metafísica del tiempo anterior residencial. Neruda, en la isla, se diseña de nuevo como el adolescente enamorado, «este torpe muchacho que te quiere», en versos que recuerdan la ingenuidad posromántica, tierna y al tiempo grandiosa de los Veinte poemas:

\section{Ríete de la noche \\ del día, de la luna, \\ ríete de las calles \\ torcidas de la isla, \\ ríete de este torpe \\ muchacho que te quiere \\ (...) \\ Niégame el pan, el aire, \\ la luz, la primavera, \\ pero tu risa nunca \\ porque me moriría.}

Inevitablemente, el mar y la isla, los escenarios habituales de un tiempo lejano de poesía amorosa, han hecho surgir con fuerza al poeta ingenuo que nos quiere contar otra vez, estremecidamente, sólo que está enamorado.

\section{SEXTA MEMORIA}

El Neruda de las cosas elementales, de la materia elemental. Las Odas como un ciclo de escritura, iniciado hacia 1952 y presente ya en 1954 con la publicación de Odas elementales, obra a la que continúa Nuevas odas elementa-
Les, Tercer Libro de Odas y Navegaciones y regresos. El origen de aquel lenguaje está en las prefiguraciones surgidas en el canto a la materia en los tres cantos materiales de la segunda Residencia en la tierra. O también, como señaló Sainz de Medrano ${ }^{8}$, en el bodegón de "Explico algunas cosas":

\section{Todo}

eran grandes voces, sal de mercaderías,

aglomeraciones de pan palpitante...

Un lenguaje diverso sobre el que comprobamos una impronta de Ramón Gómez de la Serna y, por su origen madrileño en 1935, un seguro paralelismo con el tratamiento de la materia que el escultorAlberto Sánchez o la pintora Maruja Mallo, o el pintor Benjamín Palencia, o el poeta Miguel Hernández, creaban como confluencia y como entorno del propio Neruda en lo que se llamó «Escuela de Vallecas».

Pero volvamos a la memoria. Una utilísima y suculenta. Un día en Córdoba un grupo de investigación alimentario, en el que hay desde médicos o historiadores a profesores de literatura, te pone en el brete de, quizá por el único mérito de tener algunos quilos de más, hablar sobre literatura y alimentación. Neruda sirve también para situaciones así. Su recetario, contenido en las odas, nos lleva al poeta a las cocinas, como al congrio desollado:

Ahora
recoges ajos,
acaricia primero
ese marfil precioso,
huele
su fragancia iracunda,
entonces
deja el ajo picado
caer con la cebolla
y el tomate
hasta que la cebolla
tenga color de oro.
Mientras tanto
se cuecen
con el vapor
los regios
camarones marinos
y cuando ya llegaron
a su punto,
cuando cuajó el sabor
en una salsa


formada por el jugo

del océano

y por el agua clara

que desprendió la luz de la cebolla,

entonces

que entre el congrio

y se sumerja en gloria,

que en la olla

se aceite,

se contraiga y se impregne...

La "Oda al caldillo de Congrio" es una receta que funciona y que yo les recomiendo a todos ustedes sobre todo en estos tiempos en el que algunos están dispuestos a negarnos la utilidad de la literatura.

\section{SÉPTIMA MEMORIA}

Recupero fragmentos finales de una escritura que fue muy amplia, aluvial, repleta de subidas y bajadas, pero en cualquier caso una escritura que sigo considerando imprescindible. Recupero la lectura de un texto, Memorial de isla negra. La obra se publica en 1964. No hace falta que explique que el memorial no procede ni de una isla ni mucho menos de una isla negra. Una zona costera, y turística ahora, en donde hay un hotel llamado La carreta que intenta hacer su oferta basándose en Neruda y en la casa y la memoria del poeta son la última actualidad que conozco de la isla de la memoria. (Escrito el texto, recorres a los pocos días en compañía de Nelson Osorio la casa del poeta en Isla negra. Nelson no había vuelto desde unos meses antes del golpe del 73, con Neruda vivo. La casa está llena de turistas en peregrinación. Neruda hace 25 años que no está).

El Memorial... Neruda ha cumplido sesenta años cuando lo publica. Es una forma de regalarse en su aniversario: reconstruir el pasado y la juventud ya distante a base de amores, historia, Rangoom, España, Chile, amigos, recuerdos precisos, en una poesía impetuosa, coloquializada, llena de referencias explícitas y de guiños hacia la obra anterior. Cualquier taxónomo de intertextualidades nerudianas hará bien en no perder de vista el Memorial de Isla negra cuando quiera repasar los momentos precedentes. Comprobará así que el hábitat memorial nerudiano es un recuento pormenorizado de los motivos centrales de la poética anterior, como autobiogra- fismo aquí, como memoria personal, como contraseña que en prosa sustentó la escritura de Confieso que he vivido. Si en la obra identificamos más a las mujeres y la experiencia de los Veinte poemas, llamadas ahora Terusa y Rosaura, a Josie Bliss, la birmana con la que convivió en Rangoom, a Delia del Carril, en la experiencia española, es porque identificamos múltiples situaciones, naturalezas, historias, tiempos, que estos nombres contribuyen a densificar. Núcleos históricos de su poética se construyen alrededor de series llamadas «Amores» que identifican otro clima emocional que el de la historia.

En el libro, la memoria reconstruye plenitudes, pero el tiempo presente empieza a acrecentar una tonalidad que suena a veces a desolación. "Cita de invierno" marca el nuevo modular poético:

He esperado este invierno como ningún invierno se esperó por un hombre antes de mí, todos tenían citas con la dicha:

sólo yo te esperaba, oscura hora.

Es éste como los de antaño, con padre y madre, con

de carbón y el relincho de un caballo en la calle? [ fuego

Es este invierno como el del año futuro,

el de la inexistencia, con el frío total

y la naturaleza no sabe que nos fuimos.

No. Reclamé la soledad circundada

por un gran cinturón de pura lluvia

y aquí mi propio océano me encontró con el viento volando como un pájaro entre dos zonas del agua.

Todo estaba dispuesto para que llore el cielo.

El fecundo cielo de un solo suave párpado

dejó caer sus lágrimas como espadas glaciales

y se cerró como una habitación de hotel

el mundo: cielo, lluvia y espacio.

Creo que es en esta tonalidad en donde encontramos al mejor Neruda, el que se reconstruye en un tiempo final por medio de ocho libros que aparecieron póstumos y en los que la presencia de la muerte alterna con supervivencias esperanzadas de todo lo que ha estado escribiendo hasta aquí. Un leve humor, que definí como «humor a contramuerte» en el Libro de las preguntas va contrapunteando la sensación de acabamiento. El poeta nos dice cosas ahora como:

Si he muerto y no me he dado cuenta a quién le pregunto la hora?
9

Una anécdota: mi primer artículo en una revista se llamó "Pablo Neruda: obra póstuma" y apareció publicado en la Revista "Idealidad» de la Caja de Ahorros del Mediterráneo, entonces llamada del Sureste, en 1974. 

da: intérprete de nuestro siglo", Revista de Occidente, $\mathrm{n}^{\circ}$ 86-87, julio-agosto de 1988, pág. 96.
Neruda y nosotros, los de entonces JOSÉ CARLOS ROVIRA
Estamos ante el final, en cuanto tiempo histórico, construido por varios libros póstumos, donde hay además otro estilo en Neruda. En cualquier caso, para esa memoria torpe que construyo ahora, hay una profecía imprescindible que me va a servir para empezar a terminar esto. Es la profecía histórica del libro 2000 en donde el poeta crea inicialmente una imagen desolada:

Piedad para estos siglos y sus
sobrevivientes
alegres o maltrechos, lo que no hicimos
fue por culpa de nadie, faltó acero:
lo gastamos en tanta inútil destrucción,
no importa en el balance nada de esto:
los años padecieron de pústulas y guerras,
años desfallecientes cuando tembló la
$\quad$ esperanza
en el fondo de las botellas enemigas.
[...] $\quad$ Se murió la verdad y se pudrió en tantas
$\quad$ fosas:
en este año nupcial no hay derrotados:
pongámonos cada uno máscaras
$\quad$ victoriosas.

Desde este tono inicial de desolación y de máscaras el poeta va reconstruyendo un espacio de esperanza a pesar de todo lo que se ha vivido, un espacio celebrativo, entretejido a la tristeza de la propia sensación de muerte, que sin embargo consigue llevarnos al tono de "Celebración» última que quizá es el poema con el que algunos deberemos brindar el próximo 31 de diciembre. Dice así:

Pongámonos los zapatos, la camisa listada, el traje azul aunque ya brillen los codos, pongámonos los fuegos de bengala y de artificio, pongámonos vino y cerveza entre el cuello y los pies, porque debidamente debemos celebrar este numero inmenso que costó tanto tiempo, tantos años y días en paquetes, tantas horas, tantos millones de minutos, vamos a celebrar esta inauguración.

Desembotellemos todas las alegrías resguardadas y busquemos alguna novia perdida que acepte una festiva dentellada. Hoy es. Hoy ya ha llegado. Pisamos el tapiz del interrogativo milenio. El corazón, la almendra de la época creciente, la uva definitiva irá depositándose en nosotros, y será la verdad tan esperada.
Hoy es hoy, Ha llegado este mañana preparado por mucha oscuridad: no sabemos si es claro todavía este mundo recién inaugurado: lo aclararemos, lo oscureceremos hasta que sea dorado y quemado como los granos duros del maíz...

Una profecía optimista para el 2000 que enlaza con inevitables pueblos recientes, pueblos crecientes y nuevas banderas que emergen. Un Neruda incorregible y final que nos da finalmente otra lección de esperanza. Y éste sí que es un significado que quiero retener. Utilicé otra vez ya un sentido que estableció el profesor Bellini y voy a recordarlo de nuevo como síntesis quizá de por qué esta poética se enlaza como una enredadera tantas veces a nuestra memoria. Es la idea de «intérprete de nuestro siglo» que Giuseppe Bellini ${ }^{10}$ sintetizó así:

Sus versos tienen ya puesto permanente en la casa de la poesía y en nuestro espíritu; han marcado profundamente una época, la historia interna y externa de un siglo con su sello dramático pero también con una obstinada esperanza, una inquebrantable fe en un futuro de signo feliz. En otra ocasión he definido a Neruda como inventor incansable de utopías: felices utopías que permiten resistir el embate de la desesperanza, frente a la maldad y la injusticia. Neruda ha sido efectivamente el intérprete de un siglo. Ninguno como él lo ha vivido con tanta intensidad y pasión. Podemos decir todo lo que parezca en torno a su "humanidad», criticarlo por sus equivocaciones políticas, de las que a veces, con bastante torpeza, intentó justificarse o rescatarse, pero nadie puede negarle la función de intérprete de toda una época. A través de su verso el mundo de los vejados, las razas vencidas, los pueblos oprimidos, han encontrado su voz.

Y quizá debería terminar con esta síntesis con la que estoy en total acuerdo,pero me van a permitir que deje entrar para finalizar una

\section{ÚLTIMA MEMORIA}

Cazo otra memoria. Será la última. 23 de setiembre de 1973. Hay una imagen de un joven y otros y unos adultos en la Avenida de Valladolid sin número, Prisión Provincial de Palencia. Oyen un pequeño transistor en una 
celda. Llevan días de inquietud por lo que se vive fuera. Han visto en la hora de televisión, desde el 11 de septiembre, algunas pocas imágenes que cerraban un período de historia. Entre ellas, la que más quedó en la retina, es aquella de la manta rayada con la que unos bomberos sacaban el cuerpo acribillado de Salvador Allende. Han pasado días y el diario hablado de las dos y media emite lacónicamente: «El Premio Nobel de Literatura de 1971, el poeta Pablo Neruda, ha fallecido tras una larga enfermedad en un Hospital de Santiago de Chile». Una breve biografía. Sigue el laconismo militar de su estilo en la memoria de aquellos años.

Neruda ha muerto. Las memorias de Matilde Urrutia ${ }^{11}$ recrearán las horas finales en un hospital vigilado, con los embajadores de Suecia, México, Italia y Francia pendientes desde hacia días por si se podía trasladar al poeta a otra parte. Entre los recuerdos de Matilde un balbuceo agónico y delirante: «Los están matando a todos, los están matando a todos», repite a veces el poeta. Esa tarde del 23 de septiembre se acumulan mares, vientos y recuerdos:

Ahí está el mar? Muy bien, que pase.

Dadme la gran campana, la de raza verde.

No ésa no es, la otra, la que tiene

en la boca de bronce una ruptura,

y ahora, nada más, quiero estar solo

con el mar principal y la campana.

Quiero no hablar por una larga vez,

silencio, quiero aprender aún,

quiero saber si existo.

El recuerdo nos ha traído una secuencia histórica ineludible, porque todavía es actual. El poeta tuvo tiempo de dictar o escribir algo en aquellos días para cerrar sus memorias Confieso que be vivido:

escribo estas rápidas líneas para mis memorias a sólo tres días de los hechos incalificables que llevaron a la muerte a mi gran compañero el presi- dente Allende. Su asesinato se mantuvo en silencio; fue enterrado secretamente; sólo a su viuda le fue permitido acompañar aquel inmortal cadáver. La versión de los agresores es que hallaron su cuerpo inerte, con muestras visibles de suicidio. La versión que ha sido publicada en el extranjero es diferente. A renglón seguido del bombardeo entraron en acción los tanques, muchos tanques, a luchar intrépidamente contra un solo hombre: el presidente de la República de Chile, Salvador Allende, que los esperaba en su gabinete, sin más compañía que su gran corazón, envuelto en humo y llamas. Tenían que aprovechar una ocasión tan bella. Había que ametrallarlo porque jamás renunciaría a su cargo. Aquel cuerpo fue enterrado secretamente en un sitio cualquiera. Aquel cadáver que marchó a la sepultura acompañado por una sola mujer que llevaba en sí misma todo el dolor del mundo, aquella gloriosa figura muerta iba acribillada y despedazada por las balas de las ametralladoras de los soldados de Chile, que otra vez habían traicionado a Chile ${ }^{12}$.

Final de viaje y de memoria para un poeta en el tiempo que ha pasado, donde tristemente llegó a simbolizar el final de un período tras el que se abría otro de violencia e ignominia en todos los países del Cono Sur. Final del viaje y de los recorridos por la memoria aquí precisamente, el 23 de septiembre de 1973:

Hoy es hoy y ayer se fue, no hay duda.

Hoy es también mañana, y yo me fui

con algún año frío que se fue, se fue conmigo y me llevó aquel año.

De esto no cabe duda. Mi osamenta consistió, a veces, en palabras duras como huesos al aire y a la lluvia, y pude celebrar lo que sucede dejando en vez de canto o testimonio un porfiado esqueleto de palabras.

Final de viaje y de memoria con la que intentamos evocar, precisamente estos días, un porfiado esqueleto de palabras.
11 Matilde Urrutia, Mi vida junto a Pablo Neruda, Barcelona, SeixBarral, 1996.1

12

Pablo Neruda, Confieso que he vivido, Barcelona, Seix Barral, 1974, págs. 477-478. 